\title{
Efeito da suplementação de leucina sobre a mitofagia durante a diferenciação de mioblastos
}

\author{
Chayamiti Millena Tye*, Severino Matheus Brandemarte, Luchessi Augusto Ducati, Baptista Igor Luchini.
}

\begin{abstract}
Resumo
A mitofagia é um processo caracterizado pela autofagia seletiva de mitocôndrias disfuncionais, a fim de garantir a qualidade das organelas e das funções exercidas por estas nas vias metabólicas. Alguns estudos têm demonstrado que este processo precede a diferenciação de mioblastos e a biogênese mitocondrial, permitindo que ocorra a reorganização celular do meio. Nesse sentido, torna-se intrigante o efeito de leucina sobre mitofagia durante a diferenciação de mioblastos.
\end{abstract}

\section{Palavras-chave: \\ Leucina, mitofagia, mioblastos.}

\section{Introdução}

A mitofagia é um processo de extrema importância caracterizado pela autofagia seletiva de mitocôndrias disfuncionais, a fim de garantir a qualidade das organelas e das funções exercidas por estas nas vias metabólicas. Leucina, um aminoácido essencial, tem sido descrito como um importante nutriente capaz de influenciar em diversos processos moleculares, acentuando o processo de diferenciação de mioblastos, e sendo capaz de induzir a biogênese mitocondrial, por exemplo. Alguns estudos têm demonstrado que a mitofagia precede a diferenciação de mioblastos e a biogênese mitocondrial, permitindo que ocorra a reorganização celular do meio. Nesse sentido, o estudo do efeito de leucina sobre mitofagia durante a diferenciação de mioblasto torna-se de extrema relevância para melhor entendimento do tema, assim como verificar os níveis e localização de parkin nesse processo.

\section{Resultados e Discussão}

Células $\mathrm{C} 2 \mathrm{C} 12$ foram submetidas à um protocolo de 6 dias de tratamento com três diferentes concentrações de leucina $(0,5 \mathrm{mM} ; 1 \mathrm{mM} ; 2 \mathrm{mM})$ após 2, 4 e 6 dias de diferenciação.

A fim de analisar as alterações morfológicas decorrentes da suplementação de diferentes doses de leucina após 2, 4 e 6 dias de diferenciação, foi utilizado a técnica de coloração Eosina/Hematoxilina (HE). A partir disso, foi possível verificar a quantidade de células e núcleos/célula de cada grupo. Foi possível analisar que os grupos suplementados com leucina, após 2, 4 e 6 dias de diferenciação apresentaram um maior número de núcleos por fibra, de maneira proporcional ao aumento da concentração de leucine ofertada. Sugerindo, portanto, que leucina pode influenciar no processo de diferenciação através de dose dependente. Além disso, foi possível verificar que a dose de $1 \mathrm{mM}$ de leucina exerceu um maior estímulo no processo de proliferação durante os 6 dias de tratamento.

Através da técnica de Western Blot, foram analisadas 3 proteínas de interesse para nosso estudo parkin, TOM20 e DRP1 - após 4 dias de suplementação.

Pela análise de parkin, foi possível verificar um aumento da expressão dessa proteína nas doses de $0,5 \mathrm{mM}$ e $1 \mathrm{mM}$ após os dois tempos de tratamento (2 e 4 dias). Nenhuma modulação vou encontrada nos grupos suplementados com $2 \mathrm{mM}$ de leucina. Este resultado pode indicar que a leucina é capaz de regular a mitofagia através de dosesresposta.

$\mathrm{Na}$ análise de TOM20, observamos uma modulação dessa proteína em resposta à dose de $1 \mathrm{mM}$ de leucina apenas após 4 dias de tratamento. As células apresentaram um aumento de TOM20 ( 200\%), o que pode ser interessante por sugerir maior ativação do processo de biogênese mitocondrial.

Em relação à proteína $\mathrm{DRP1}$, observa-se uma modulação em reposta às diferentes doses de suplementação de leucina após 2 dias de tratamento. Os grupos tratados após 4 dias de diferenciação apresentaram uma diminuição significativa da expressão dessa proteína. Estes dados podem ser intrigantes, demonstrando que o tempo de tratamento com leucina também pode influenciar no processo de mitofagia.

\section{Conclusões}

Nossos resultados indicam que os grupos submetidos à 6 dias de tratamento com leucina apresentarem uma maior taxa de proliferação e, os grupos suplementados com leucina após 2 dias de diferenciação tiveram um maior número de núcleos por célula em relação aos demais grupos. Além disso, as células tratadas com $1 \mathrm{mM}$ de leucina durante 4 dias apresentaram um aumento na expressão de Parkin e TOM20. Indicando, portando, que leucina pode exercer um efeito regulatório no processo de mitofagia através de dose dependente. Contudo, é necessário realizar uma análise após 6 dias de diferenciação para confirmar a hipótese.

\section{Agradecimentos}

Agradecimentos ao CNPq, FAPESP, FAEPEXUNICAMP e CAPES.

SIN, J.; et al. Mitophagy is required for mitochondrial biogenesis and myogenic DAI, J.-M., et al., Leucine promotes proliferation and differentiation of primary preterm rat satellite cells in part through mTORC1 signaling pathway. Nutrients, 2015. 7(5): p. 3387-3400. differentiation of C2C12 myoblasts. Autophagy, 2016. 12(2): p369-380.

KURODA, Y., et al., Parkin affects mitochondrial function and apoptosis in neuronal and myogenic cells. Biochemical and biophysical research communications, 2006. 348(3): p. 787-793. 